\title{
Longterm Clinical Outcomes in 420 Patients with Psoriatic Arthritis Taking Anti-tumor Necrosis Factor Drugs in Real-world Settings
}

\author{
Florenzo Iannone, Simona Lopriore, Romano Bucci, Giuseppe Lopalco, Angela Chialà, \\ Luca Cantarini, and Giovanni Lapadula
}

\begin{abstract}
Objective. An observational study to evaluate the longterm clinical outcomes of adalimumab (ADA), etanercept (ETN), and infliximab (IFX) in patients with psoriatic arthritis (PsA), in real-world settings. Methods. From a prospective cohort we studied 420 biologic-naive patients with PsA who had peripheral arthritis and were beginning a treatment with ADA, ETN, or IFX. Drug survival was evaluated by Kaplan-Meier life analysis, and baseline predictors of drug discontinuation were assessed by Cox regression analysis. The frequency of concomitant glucocorticoids and the daily mean dosage were compared by chi-square test and ANOVA repeated measures across 4 years.

Results. After 4 years the overall survival of the first anti-tumor necrosis factor- $\alpha$ (anti-TNF) was $51.0 \%$, but significantly higher for ETN $(58.9 \%)$ than ADA $(43.9 \%)$ or IFX $(44.0 \% ; \mathrm{p}=0.003)$. Patients taking ETN also had the lowest HR of drug discontinuation (HR 0.57, 95\% CI 0.34-0.93, $\mathrm{p}=0.02$ ). The strongest predictor of drug interruption was female sex (HR 2.02, 95\% CI 1.28-3.20, $\mathrm{p}=0.002$ ). The disease duration was inversely correlated with drug discontinuation (HR $0.96,95 \%$ CI $0.93-0.99, \mathrm{p}=0.02)$. The average daily dose of prednisone significantly decreased from baseline: $5.6 \pm 2.5$ to $4.7 \pm 1.9$ at 1 year $(p=0.01)$ to $4.0 \pm 1.8$ at 4 years $(p=0.001)$. Additionally, compared to baseline $(49.6 \%)$, a significant reduction of patients taking glucocorticoids was detected at 2 years $(36.5 \%, \mathrm{p}<0.05), 3$ years $(29.9 \%, \mathrm{p}<0.01)$, and 4 years $(22.6 \%, \mathrm{p}<0.01)$.

Conclusion. In real-world settings, TNF inhibitors showed a high rate of drug survival at 4 years. Further, the need for glucocorticoids for controlling active PsA was lowered with time. (First Release March 15 2016; J Rheumatol 2016;43:911-17; doi:10.3899/jrheum.151042)
\end{abstract}

Key Indexing Terms:

DISEASE ACTIVITY PSORIATIC ARTHRITIS

ETANERCEPT

\section{ADALIMUMAB INFLIXIMAB}

The introduction of anti-tumor necrosis factor- $\alpha$ (anti-TNF) drugs is considered a milestone in the treatment of active psoriatic arthritis (PsA), as recommended by international

From the Rheumatology Unit, Medical School, University of Bari, Bari; the Rheumatology Unit, Ospedali Riuniti di Foggia, Foggia; and the Department of Rheumatology, Policlinico Le Scotte, University of Siena, Siena, Italy.

Dr. Iannone has received consulting fees, speaking fees, or honoraria $(<€ 10,000)$ from Pfizer, Merck, Abbott, and Bristol-Myers Squibb.

F. Iannone, MD, PhD, Associate Professor of Rheumatology,

Rheumatology Unit, Medical School, University of Bari; S. Lopriore, MD, Research Assistant of Rheumatology, Rheumatology Unit, Medical School, University of Bari; R. Bucci, MD, Consultant of Rheumatology,

Rheumatology Unit, Ospedali Riuniti di Foggia; G. Lopalco, MD,

Consultant of Rheumatology, Rheumatology Unit, Medical School, University of Bari; A. Chialà, MD, Consultant of Rheumatology,

Rheumatology Unit, Medical School, University of Bari; L. Cantarini, MD, Senior Lecturer of Rheumatology, Policlinico Le Scotte, University of

Siena; G. Lapadula, MD, Rheumatology Unit, Medical School, University of Bari.

Address correspondence to Dr. F. Iannone, Associate Professor of

Rheumatology, Interdisciplinary Department of Medicine, Rheumatology

Unit, Policlinico, Piazza G. Cesare 11, 70124 Bari, Italy.

E-mail:florenzo.iannone@uniba.it

Accepted for publication January 14, 2016 guidelines ${ }^{1}$, based on several randomized clinical trials (RCT) that have given evidence of the drugs' efficacy and short-term safety $2,3,4,5,6$. In real-world settings, a widespread surrogate measure of clinical outcomes of anti-TNF treatment is drug survival, a result of drug safety, effectiveness, and patient adherence to therapy. The longer the time of followup, the more informative the data analysis will be. Therefore, more robust data are available for the first TNF inhibitors launched on the market: adalimumab (ADA), etanercept (ETN), and infliximab (IFX). The longest observation time has been reported by the Danish registry DANBIO, in which 764 patients with PsA treated with TNF inhibitors were monitored up to 8 years ${ }^{7}$. No difference was detected among ADA, ETN, and IFX in drug survival, and male sex and higher CRP level were associated with longer drug survival ${ }^{7}$. In the Southern Sweden Arthritis Treatment Group (SSATG) registry, no significant difference among treatments was found, although ETN had half the risk of discontinuing therapy in comparison to IFX ${ }^{8}$. Nevertheless, a 5-year observational study of a small cohort of patients with active PsA found equal effectiveness with ADA, ETN, and IFX, but ETN showed the highest rate of drug persistence ${ }^{9}$.

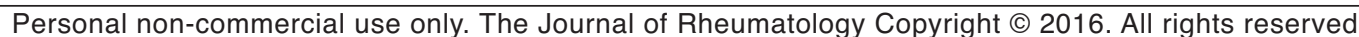


The evaluation of drug survival together with the analysis of predictors thereof may also give interesting information about the behavior of clinicians in the management of PsA, such as the administration of concomitant glucocorticoids or disease-modifying antirheumatic drugs (DMARD). However, while in RCT data on concomitant therapies are carefully gathered, in the real world data are usually available at baseline but often lacking during followup. Thus, we usually miss data on the possible effect of anti-TNF agents on use and dosage of glucocorticoids over time. The primary objective of our study was to estimate the 4-year survival of ADA, ETN, and IFX in biologic-naive patients with PsA. Further, we aimed to evaluate changes in the proportion of patients taking concomitant glucocorticoids and the average daily dose across 4 years of followup.

\section{MATERIALS AND METHODS}

Patients. We analyzed data from PsA patients within a longitudinal cohort study followed up at the outpatient rheumatology clinics of Bari, Foggia, and Siena belonging to the Gruppo Italiano Studio Early Arthritis (GISEA) registry. GISEA was launched in 2003 to record and monitor patients with rheumatoid arthritis, PsA, and spondyloarthritis who are treated with biological drugs on the basis of the standard of clinical care. The local Ethics Committee approved the GISEA registry (Trial registry no. NCT01543594), and prior written informed consent to take part was obtained from all patients, in compliance with the Helsinki declaration.

Patient data are recorded at baseline and every 6 months thereafter. The collected data include age, sex, disease duration, the intake of glucocorticoids and DMARD, 68 tender joint count (TJC), 66 swollen joint count (SJC), 28-joint Disease Activity Scores (DAS28), skin involvement by Psoriasis Area and Severity Index (PASI), C-reactive protein (CRP ml/dl), the first-hour erythrocyte sedimentation rate, rheumatoid factor, pain assessed by means of visual analog scale (VAS 0-100), Health Assessment Questionnaire (HAQ 0-3), patient's global assessment of disease activity (PtGA 0-100), side effects, and biological drug discontinuation.

For the purpose of our study, in the period 2003-2013 we consecutively analyzed 420 PsA patients with peripheral articular disease commencing their first ever anti-TNF treatment with ADA, ETN, or IFX. Inclusion criteria were (1) the presence of peripheral PsA, which was diagnosed according to the CASPAR (ClASsification criteria for Psoriatic ARthritis) criteria ${ }^{10}$ (oligoarticular or polyarticular subset were defined using a cutoff $\geq 5$ involved joints); (2) active disease, defined as DAS28 $\geq 3.2$, and $\geq 3$ swollen and tender joints ${ }^{11,12}$; and (3) failure of at least 2 DMARD among methotrexate (MTX) $15 \mathrm{mg} / \mathrm{week}$, sulfasalazine $2 \mathrm{~g} /$ day, cyclosporine $3 \mathrm{mg} / \mathrm{kg} /$ day, leflunomide $20 \mathrm{mg} /$ day for 3 months. Exclusion criteria were (1) axial involvement, diagnosed on the basis of inflammatory low back pain and sacroiliitis on imaging, according to the modified New York criteria for the diagnosis of ankylosing spondylitis; and (2) patients previously treated with a first course of anti-TNF drugs. Patients with axial disease, not enrolled in this study and excluded from the analysis, accounted for roughly $10 \%$ of our overall PsA cohort.

Patients were prescribed TNF inhibitors according to the rheumatologist's expert opinion at the doses recommended in the official guidelines: ADA $40 \mathrm{mg}$ subcutaneously every other week, ETN $50 \mathrm{mg}$ subcutaneously per week, and IFX $5 \mathrm{mg} / \mathrm{kg}$ intravenously at weeks 0,2 , and 6 , and every 8 weeks thereafter.

Outcome measures. The primary clinical outcome was the drug survival rate at 4 years and the assessment of baseline predictors thereof. Secondary outcomes investigated across 4 years were the proportion of patients taking the anti-TNF drug as monotherapy and reduction glucocorticoid intake, if any, and the clinical response evaluated as the achievement of a "good"
European League Against Rheumatism (EULAR) clinical response (defined as a DAS28 change from baseline $\geq 1.2^{13}$ ), an improvement of functional ability considered as a reduction of the HAQ score $(\triangle \mathrm{HAQ}) \geq 0.5$, and the reduction of the mean number of 66-TJC, 68-SJC, VAS pain, and PtGA from baseline.

Statistical analysis. The Kolmogorov-Smirnov test was used to check a normal distribution of continuous variables. Continuous variables were reported as means and SD if normally distributed, while medians and range were calculated for not normally distributed continuous variables. For categorical variables, counts and percentages were calculated. Differences between groups for normally distributed continuous variables were compared by ANOVA, and the Kruskal-Wallis test was used to compare not normally distributed continuous variables. Within-group comparisons between baseline and each followup time interval were evaluated by ANOVA repeated measures and posthoc Bonferroni test. Differences in the distribution of frequencies were assessed by chi-squared test. Survival of therapy was computed using the Kaplan-Meier life table method, and the log-rank test was used to compare discontinuation rates. Patients contributed to the survival models until the first discontinuation or censoring at 4 years of treatment. Patients stopping anti-TNF because of remission were right censored. The search for a possible predictor of drug discontinuation was performed by univariate and multivariate Cox regression analysis. In the multivariate model, HR of drug discontinuation were adjusted for anti-TNF drug, calendar year, age, sex, disease duration, use of glucocorticoids and DMARD at entry, baseline CRP ( $\leq 1 \mathrm{mg} / \mathrm{dl}$ vs $>1 \mathrm{mg} / \mathrm{dl}), 68$-TJC, 66-SJC, $\mathrm{HAQ}$, and oligo/polyarticular disease. Missing data were not replaced. Analyses were made using the SPSS (version 20) statistical software (IBM), and a $p$ value of $<0.05$ was considered statistically significant.

\section{RESULTS}

Baseline features. We analyzed data of 420 anti-TNF drug-naive patients with peripheral PsA [257 females $(61 \%)]$, who were beginning their first ever treatment with ADA $(n=139)$, ETN $(n=197)$, or IFX ( $=84$; Table 1$)$. There were no significant differences in age, duration of disease, sex distribution, HAQ, 68-TJC, 66-SJC, or VAS pain among the 3 arms of treatment. However, patients with PsA who were taking IFX had more active disease; DAS28 and PASI were significantly higher among them than in those taking ADA or ETN.

Drug survival and predictors. Crude drug survival curves were evaluated by Kaplan-Meier analysis. The overall retention rate at 4 years was $51.0 \%(n=214)$ in the whole PsA cohort and the mean survival time (MST) was 36.8 months (95\% CI 34.8-37.8). The survival rates at 4 years of each treatment group were $58.9 \%$ for ETN (MST 38.9, 95\% CI $37.0-40.8$ months), $44.0 \%$ for IFX (MST $36.2,95 \%$ CI 32.9-39.4 months), and $43.9 \%$ for ADA (MST 32.7, 95\% CI 29.9-35.5 months), and the difference was statistically significant (log rank test, $\mathrm{p}=0.003$; Figure 1). Cox regression analysis was used to compute estimated HR of drug discontinuation at 4 years, adjusting for calendar year, sex, age, TNF inhibitor, HAQ, CRP $\geq 1 \mathrm{mg} / \mathrm{dl}$, TJC, SJC, glucocorticoid intake, DMARD co-therapy, and oligo/polyarticular disease (Table 2). The strongest predictor of drug interruption was female sex (HR 2.02, 95\% CI 1.28-3.20, p = 0.002). Nevertheless, disease duration at entry negatively predicted drug discontinuation (HR 0.96, 95\% CI 0.93-0.99, $\mathrm{p}=0.02$ ). Considering IFX as a reference, patients taking ETN had

Personal non-commercial use only. The Journal of Rheumatology Copyright $\subset$ $\subset$ 2016. All rights reserved 
Table 1. Baseline demographics of 420 patients with PsA, subdivided by anti-TNF drug. All data are median (range) unless otherwise indicated.

\begin{tabular}{lccccc}
\hline & All, $\mathrm{n}=420$ & ADA, $\mathrm{n}=139$ & ETN, $\mathrm{n}=197$ & IFX, $\mathrm{n}=84$ & $\mathrm{p}$ \\
\hline Age, yrs & $50(16-81)$ & $46(18-72)$ & $51(16-81)$ & $50(16-77)$ & 0.24 \\
Duration, yrs & $4(0.8-39)$ & $3.3(0.8-37)$ & $3.0(0.3-35)$ & $4.5(0.4-39)$ & 0.32 \\
ESR, mm/h & $16(2-97)$ & $13(2-90)$ & $16(2-97)$ & $22(2-90)$ & 0.03 \\
CRP, mg/dl & $0.4(0.1-14)$ & $0.3(0.1-12)$ & $0.4(0.1-14)$ & $0.5(0.1-10)$ & 0.04 \\
68-TJC & $7(1-59)$ & $7(1-57)$ & $7(1-59)$ & $8(1-47)$ & 0.70 \\
66-SJC & $1(0-42)$ & $1(0-42)$ & $1(1-36)$ & $2(1-33)$ & 0.84 \\
DAS28 & $4.3(1.4-8.6)$ & $4.1(1.4-7.1)$ & $4.2(1.6-8.6)$ & $4.8(1.8-8.4)$ & 0.02 \\
HAQ & $1.12(0.1-3.0)$ & $1.12(0.1-2.75)$ & $1.12(0.1-3.0)$ & $1.25(0.1-3.0)$ & 0.81 \\
VAS-Pain & $70(10-100)$ & $60(10-100)$ & $70(10-100)$ & $70(10-100)$ & 0.55 \\
PtGA & $70(10-100)$ & $60(10-100)$ & $70(10-100)$ & $70(10-100)$ & 0.06 \\
PASI & $1.2(0-47)$ & $1.2(0-47)$ & $0.8(0-18)$ & $6.3(0-14)$ & 0.01 \\
Predn (mg/day) & $5.0(2.5-25)$ & $5.0(2.5-10)$ & $5.0(2.5-15)$ & $5.0(2.5-25)$ & 0.08 \\
Female, $\mathrm{n}(\%)$ & $257(61)$ & $85(61)$ & $122(62)$ & $50(60)$ & 0.91 \\
CRP > 1, n (\%) & $110(29)$ & $28(23)$ & $53(28)$ & $29(37)$ & 0.14 \\
Predn, $\mathrm{n}(\%)$ & $204(50)$ & $67(50)$ & $102(52)$ & $35(43)$ & 0.38 \\
DMARD, n $(\%)$ & $245(60)$ & $87(64)$ & $106(54)$ & $52(64)$ & 0.11 \\
\hline
\end{tabular}

PsA: psoriatic arthritis; TNF: tumor necrosis factor; ADA: adalimumab; ETN: etanercept; IFX: infliximab; ESR: erythrocyte sedimentation rate; CRP: C-reactive protein; DAS28: 28-joint Disease Activity Score; 68-TJC: 68 joint tender joint count; 66-SJC: 66 joint swollen joint count; VAS: visual analog scale; HAQ: Health Assessment Questionnaire; PtGA: patient's global assessment of disease activity; PASI: Psoriasis Area and Severity Index; DMARD: disease-modifying antirheumatic drugs; Predn: prednisone.

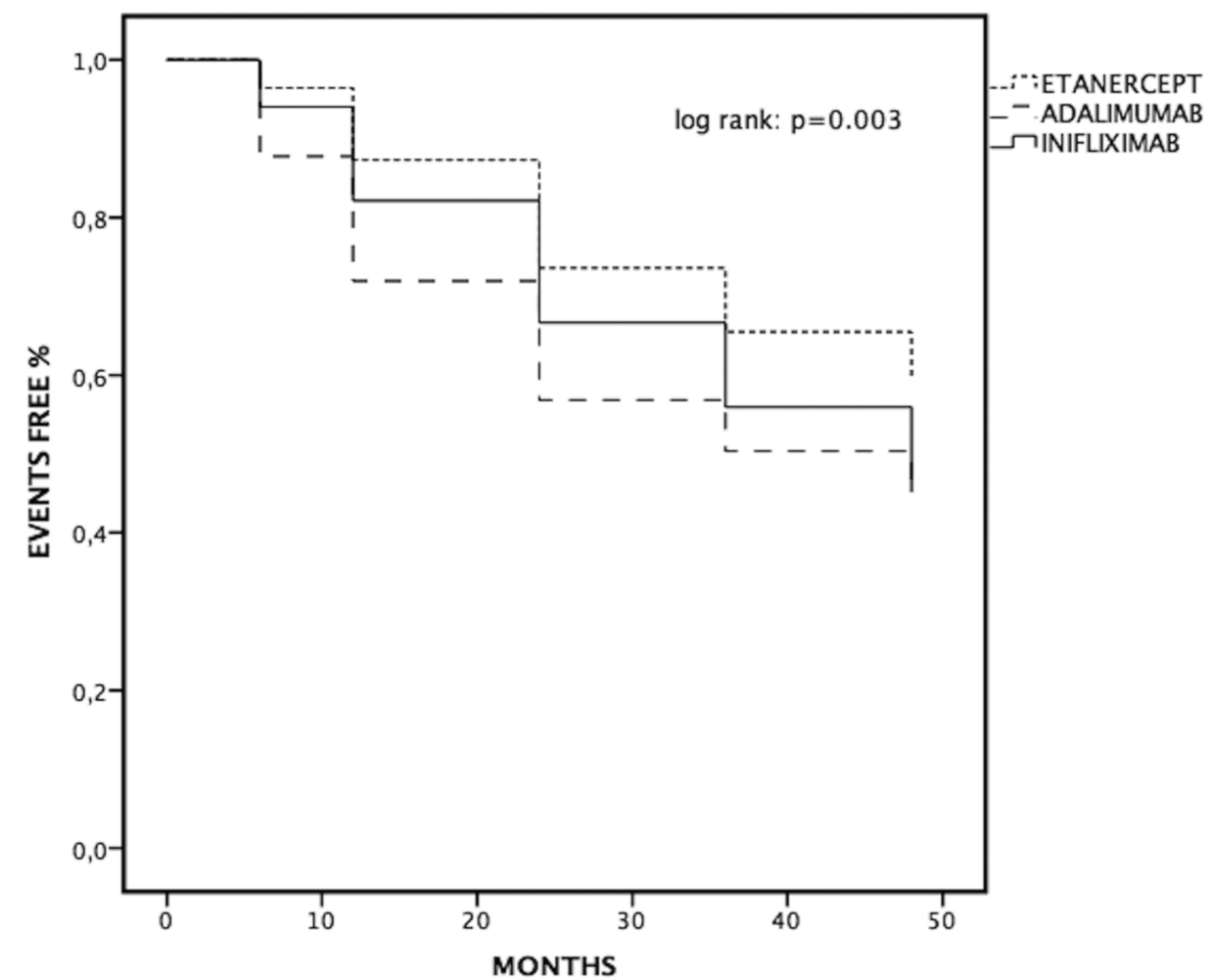

Figure 1. Four-year crude retention rates of anti-TNF therapy in patients with PsA by drug. TNF: tumor necrosis factor; PsA: psoriatic arthritis.

around $40 \%$ less HR of drug withdrawal (HR $0.57,95 \% \mathrm{CI}$ $0.34-0.93, \mathrm{p}=0.02)$.
Clinical outcomes. Outcomes of anti-TNF therapy were assessed after 6 months, 12 months, and every year thereafter.

Personal non-commercial use only. The Journal of Rheumatology Copyright @ 2016 . All rights reserved. 
Table 2. HR estimates of anti-TNF discontinuation at 4 years by univariate and multivariate Cox regression analysis.

\begin{tabular}{lcccccc}
\hline & \multicolumn{3}{c}{ Univariate } & \multicolumn{3}{c}{ Multivariate } \\
\hline Baseline covariates & HR & $95 \%$ CI & $\mathrm{p}$ & HR & $95 \%$ CI & $\mathrm{p}$ \\
Age & 0.99 & $0.98-1.00$ & 0.79 & 0.99 & $0.98-1.01$ & 0.88 \\
Sex, female/male & 1.75 & $1.20-2.36$ & 0.001 & 2.02 & $1.28-3.20$ & 0.002 \\
Disease duration & 0.97 & $0.94-1.00$ & 0.64 & 0.96 & $0.93-0.99$ & 0.02 \\
Oligo/polyarticular & 0.78 & $0.58-1.05$ & 0.11 & 1.20 & $0.73-1.99$ & 0.45 \\
CRP, $\geq 1$ mg/dl / < 1 mg/dl & 0.93 & $0.67-1.29$ & 0.67 & 1.29 & $0.83-1.89$ & 0.25 \\
68-tender joint count & 1.01 & $1.00-1.02$ & 0.04 & 1.00 & $0.98-1.02$ & 0.71 \\
66-swollen joint count & 1.00 & $0.97-1.03$ & 0.74 & 0.99 & $0.95-1.03$ & 0.75 \\
HAQ & 1.20 & $0.97-1.48$ & 0.79 & 1.16 & $0.85-1.59$ & 0.32 \\
Calendar year & 1.02 & $0.97-1.07$ & 0.36 & 1.06 & $0.99-1.13$ & 0.94 \\
DMARD, yes/no & 1.03 & $0.77-1.38$ & 0.80 & 0.89 & $0.61-1.30$ & 0.65 \\
Prednisone, yes/no & 1.00 & $0.76-1.33$ & 0.96 & 1.08 & $0.74-1.58$ & 0.65 \\
Drug $\quad$ & & & & & & \\
$\quad$ Infliximab & 1 & & & & & \\
$\quad$ Adalimumab & 1.10 & $0.77-1.58$ & 0.58 & 0.93 & $0.56-1.54$ & 0.79 \\
$\quad$ Etanercept & 0.68 & $0.48-0.98$ & 0.04 & 0.57 & $0.34-0.93$ & 0.02 \\
\hline
\end{tabular}

TNF: tumor necrosis factor; CRP: C-reactive protein; HAQ: Health Assessment Questionnaire; DMARD:

disease-modifying antirheumatic drug.

A secondary endpoint of the study was evaluation of the intake of glucocorticoids over time, as either daily dosage or percentage of patients, and changes in the concomitant therapy with DMARD. At baseline, the average daily dose of prednisone was $5.6 \pm 2.5$, and it progressively decreased to $5.2 \pm 2.4$ at 6 months, $4.7 \pm 1.9$ at 1 year $(\mathrm{p}=0.01), 4.6 \pm$
1.9 at 2 years $(p=0.01), 4.6 \pm 2.0$ at 3 years $(p=0.01)$, and $4.0 \pm 1.8$ at 4 years $(p=0.001)$. Additionally, a gradual reduction of percentage of patients taking prednisone or DMARD in combination with anti-TNF drugs was seen with time (Figure 2). Compared to baseline (49.6\%), a significantly lower percentage of patients taking glucocorticoids

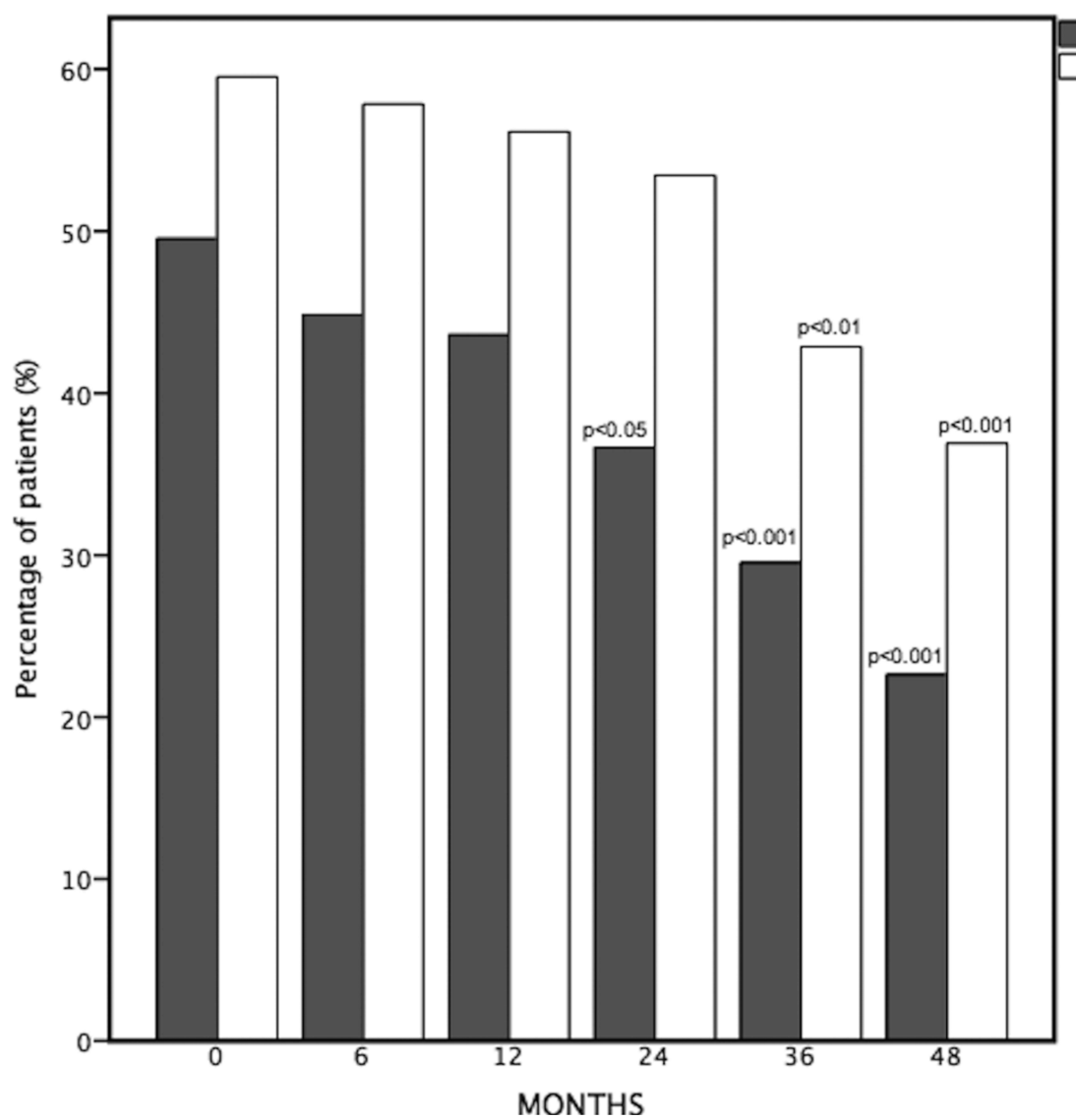

Steroids

DDMARDs

Personal non-commercial use only. The Journal of Rheumatology Copyright $@$ 2016. All rights reserved 
was detected at 2 years $(36.5 \%, \mathrm{p}<0.05), 3$ years $(29.9 \%$, $\mathrm{p}<0.001)$, and 4 years $(22.6 \%, \mathrm{p}<0.001)$. Likewise, the percentage of patients taking co-therapy with DMARD was $59.6 \%$ at entry, $43.1 \%(\mathrm{p}<0.01)$ at 3 years, and $36.9 \%(\mathrm{p}<$ $0.001)$ at 4 years.

Because of the baseline differences among anti-TNF treatments, we studied the percentage of patients achieving an improvement of the DAS28 score $\geq 1.2$ ("good" EULAR response) from baseline, and the percentage of patients showing a reduction of the HAQ score $(\triangle \mathrm{HAQ}) \geq 0.5$. As shown in Table 3, the percentage of patients attaining a "good" EULAR response was significantly higher in IFX at 3 and 4 years of followup. However, the frequency of PsA patients with meaningful improvement of functional ability was not statistically different $(\triangle \mathrm{HAQ} ; \geq 0.5)$ among treatments, except for IFX at 1 year.

We also assessed the effect of anti-TNF therapy on 68-TJC, 66-SJC, HAQ, and DAS28 (Figure 3A), and VAS-pain and PtGA (Figure 3B) in the whole PsA cohort over time. VAS-pain significantly dropped from $62.2 \pm 24$ at entry to $23.4 \pm 28$ at 6 months $(\mathrm{p}=0.001)$ and remained steady up to 4 years $(21.9 \pm 27, \mathrm{p}=0.001)$. Likewise, PtGA significantly decreased from $66.7 \pm 25$ at entry to $23.9 \pm 28$ at 6 months $(\mathrm{p}=0.001)$ and further declined until 4 years $(22.6 \pm 27, p=0.001)$. Also the mean of 68-TJC dropped from $10.3 \pm 10$ at entry to $2.4 \pm 5.2$ at 6 months $(\mathrm{p}=0.001)$ and $1.5 \pm 3.8$ at 4 years $(\mathrm{p}=0.001)$. Additionally, the number of 66-SJC was $2.7 \pm 4.6$ at baseline, significantly reduced at 6 months $(0.26 \pm 0.7, \mathrm{p}=0.001)$, and at 4 years $(0.16 \pm 0.6$, $\mathrm{p}=0.001)$. Baseline HAQ was $1.1 \pm 0.6,0.37 \pm 0.6$ at 6 months, and $0.44 \pm 0.6$ at 4 years $(\mathrm{p}=0.001)$. At entry, DAS2 8 was $4.4 \pm 1.3,2.2 \pm 1.2$ at 6 months, and $2.2 \pm 1.0$ at 4 years $(\mathrm{p}=0.001)$.

Anti-TNF therapy was globally safe and well tolerated. Adverse events that led to treatment discontinuation occurred in 48 patients $(11.4 \%)$. The most frequent $(n=13)$ was rash at the site of injection, followed by infusion reaction $(n=5)$ and flare of skin psoriasis $(\mathrm{n}=3)$.

Table 3. Clinical outcomes of anti-TNF treatment up to 4 years in patients with psoriatic arthritis. Frequencies of patients achieving a "good" EULAR response or HAQ improvement $\geq 0.5$ from baseline (DHAQ) are given. Adalimumab (ADA), etanercept (ETN), and infliximab (IFX) are compared by chi-squared test. Except for $\mathrm{p}$ values, data are percentages.

\begin{tabular}{lcccccccc}
\hline & \multicolumn{3}{c}{ "Good" EULAR Response } & \multicolumn{4}{c}{$\Delta \mathrm{HAQ} \geq 0.5$} \\
& ADA & ETN & IFX & p & ADA & ETN & IFX & p \\
\hline 6 mos & 59 & 70 & 71 & 0.13 & 49 & 57 & 46 & 0.12 \\
$1 \mathrm{yr}$ & 59 & 73 & 78 & 0.02 & 55 & 65 & 75 & 0.04 \\
$2 \mathrm{yrs}$ & 70 & 74 & 85 & 0.17 & 63 & 66 & 69 & 0.75 \\
$3 \mathrm{yrs}$ & 67 & 76 & 85 & 0.04 & 58 & 62 & 57 & 0.62 \\
$4 \mathrm{yrs}$ & 61 & 79 & 83 & 0.04 & 61 & 56 & 61 & 0.79 \\
\hline
\end{tabular}

TNF: tumor necrosis factor; EULAR: European League Against Rheumatism; HAQ: Health Assessment Questionnaire.

\section{DISCUSSION}

The aim of our study was to estimate the 4-year retention of the anti-TNF drugs ADA, ETN, and IFX, in biologic-naive patients with peripheral PsA. We previously reported the 2-year data showing that ETN had the longest survival in polyarticular peripheral PsA ${ }^{14}$. Here, we extended the observation to 4 years and assessed the changes in glucocorticoid usage over time. We analyzed 420 patients with PsA and the overall drug persistence at 4 years was $48 \%$, very close to that reported by the regional biologics registry of the $\mathrm{SSATG}^{8}$. The Norway registry NOR-DMARD reported a crude retention rate of $57 \%$ at 3 years ${ }^{15}$, and the Danish registry DANBIO reported the same rate of drug survival $(57 \%)$ but at 2 years 7 . Obviously, the former is a mere list of rates that cannot be compared because several confounding factors made our cohorts quite different. Unlike the NOR-DMARD $^{15}$ or DANBIO ${ }^{7}$ study, in our analysis ETN showed a significantly higher survival at 4 years. But in a small cohort of 65 patients with PsA from Greece ${ }^{9}$, the ETN survival rate was the highest at 5 years followup. Nevertheless, in the study from SSATG, 8 patients with PsA starting ETN showed about half of the hazard of stopping the therapy compared to IFX. Similarly, in our appraisal patients taking ETN had $40 \%$ less likelihood than those taking IFX to discontinue the treatment at 4 years. The only other covariate strongly correlating with drug interruption was female sex, as in $\mathrm{DANBIO}^{7}$ or in the British Society for Rheumatology Biologics Register ${ }^{16}$. We did not find correlations between drug survival and CRP levels or DMARD comedication, as reported $7,8,17$. More recently, a French survey has shown comorbid cardiovascular diseases as the only predictor of the discontinuation of the first anti-TNF $\operatorname{drug}^{18}$.

Focusing on the effect of DMARD co-administration, it should be considered that in the NOR-DMARD registry, the combination of MTX with an anti-TNF drug did not yield a better clinical response than anti-TNF monotherapy, and that the effect of MTX on longer drug survival was seen only for $\mathrm{IFX}^{17}$. In the DANBIO registry, the concomitant use of MTX at baseline did not affect the drug persistence, but in the multivariate regression model, the lack of MTX was correlated with anti-TNF drug discontinuation ${ }^{7}$. Further, in the SSATG registry concomitant MTX improved TNF drug adherence by reducing the number of dropouts for adverse events $^{8}$. These discrepancies, apart from several confounding factors, might occur because in the retrospective analysis from registries, concomitant DMARD treatment is often related to baseline, while information about ongoing DMARD therapy is often missing or incomplete. In our study, data on DMARD and glucocorticoid dosage were collected or retrieved from patient charts over time, and we showed that DMARD combination significantly dropped from $58.4 \%$ at entry to $42.9 \%$ at 3 years, and further decreased to $37.8 \%$ at 4 years. These findings may explain

Personal non-commercial use only. The Journal of Rheumatology Copyright @ 2016. All rights reserved. 

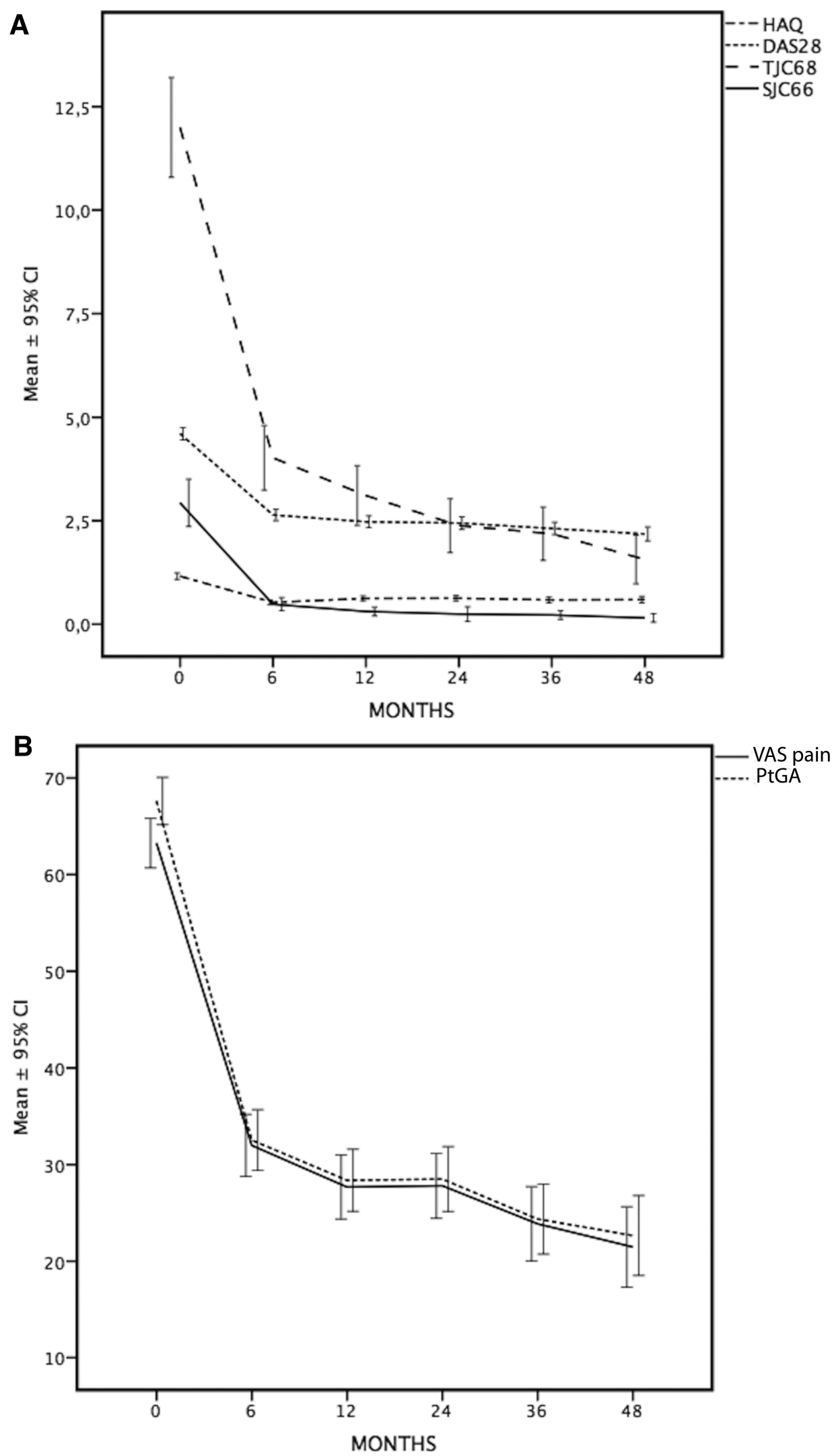

Figure 3. Four-year values (mean \pm 1 SD). A. 68 tender joint count (TJC), 66 swollen joint count (SJC), 28-joint disease Activity Scores (DAS28), Health Assessment Questionnaire (HAQ). B. Visual analog scale (VAS) of pain, patient global assessment of disease activity (PtGA). A rapid decrease is shown at 6 months that was sustained up to 48 months.

Personal non-commercial use only. The Journal of Rheumatology Copyright @ 2016 . All rights reserved. 
why baseline DMARD co-therapy does not correlate with clinical outcomes in all studies, and provide evidence that in settings of standard care, Italian rheumatologists tend to stop concomitant DMARD once a clinical improvement is achieved in patients with PsA taking anti-TNF therapy.

The secondary endpoint of this analysis was to assess the possible effect of TNF inhibitors on glucocorticoid intake in PsA, and we have shown that the frequency of patients taking prednisone and its mean daily dosage significantly decreased during 4 years of followup. However, a controlled trial is needed to confirm a definitive steroid-sparing effect of anti-TNF treatment. The effectiveness of anti-TNF therapy was assessed by "good" EULAR response, changes in 68-TJC and 66-SJC, and patient-reported outcomes. The percentage of patients attaining a "good" EULAR response ranged between $59 \%$ and $73 \%$ at 6 months and increased up to $64 \%-86 \%$ at 4 years. Patients taking IFX had the best response rates probably because they had the highest disease activity, and DAS28 decrease $\geq 1.2$ from baseline was easier to achieve. At 6 months, 68-TJC and 66-SJC as well as HAQ, PtGA, and VAS pain rapidly dropped and then further decreased slightly up to 4 years.

Our study has the usual drawbacks of retrospective analysis such as the lack of randomization of unselected patients or the bias of channeling PsA patients with more active disease who were taking IFX. Thus, definite conclusions cannot be drawn about the longterm effectiveness of different anti-TNF drugs. Nevertheless, there are some strong points to be highlighted, such as the high 4-year drug survival of TNF blocking agents and the sustained good clinical outcomes in PsA. Finally, to our knowledge, this is the first study from real-world settings showing how anti-TNF treatment is associated with a meaningful lowering of glucocorticoid need across years.

\section{REFERENCES}

1. Ash Z, Gaujoux-Viala C, Gossec L, Hensor EM, FitzGerald O, Winthrop K, et al. A systematic literature review of drug therapies for the treatment of psoriatic arthritis: current evidence and meta-analysis informing the EULAR recommendations for the management of psoriatic arthritis. Ann Rheum Dis 2012;71:319-26.

2. Gladman DD, Mease PJ, Ritchlin CT, Choy EH, Sharp JT, Ory PA, et al. Adalimumab for long-term treatment of psoriatic arthritis: forty-eight week data from the adalimumab effectiveness in psoriatic arthritis trial. Arthritis Rheum 2007;56:476-88.

3. Goulabchand R, Mouterde G, Barnetche T, Lukas C, Morel J, Combe B. Effect of tumour necrosis factor blockers on radiographic progression of psoriatic arthritis: a systematic review and meta-analysis of randomised controlled trials. Ann Rheum Dis 2014;73:414-9.

4. Heiberg MS, Kaufmann C, Rødevand E, Mikkelsen K, Koldingsnes W, Mowinckel P, et al. The comparative effectiveness of anti-TNF therapy and methotrexate in patients with psoriatic arthritis: 6 month results from a longitudinal, observational, multicentre study. Ann Rheum Dis 2007;66:1038-42.
5. Kavanaugh A, Krueger GG, Beutler A, Guzzo C, Zhou B, Dooley LT, et al. Infliximab maintains a high degree of clinical response in patients with active psoriatic arthritis through 1 year of treatment: results from the IMPACT 2 trial. Ann Rheum Dis 2007;66:498-505.

6. Mease PJ, Goffe BS, Metz J, VanderStoep A, Finck B, Burge DJ. Etanercept in the treatment of psoriatic arthritis and psoriasis: a randomised trial. Lancet 2000;356:385-90.

7. Glintborg B, Østergaard M, Dreyer L, Krogh NS, Tarp U, Hansen MS, et al. Treatment response, drug survival, and predictors thereof in 764 patients with psoriatic arthritis treated with anti-tumor necrosis factor $\alpha$ therapy: results from the nationwide Danish DANBIO registry. Arthritis Rheum 2011;63:382-90.

8. Kristensen LE, Gülfe A, Saxne T, Geborek P. Efficacy and tolerability of anti-tumour necrosis factor therapy in psoriatic arthritis patients: results from the South Swedish Arthritis Treatment Group register. Ann Rheum Dis 2008;67:364-9.

9. Saougou I, Markatseli TE, Papagoras C, Voulgari PV, Alamanos Y, Drosos AA. Sustained clinical response in psoriatic arthritis patients treated with anti-TNF agents: a 5-year open-label observational cohort study. Semin Arthritis Rheum 2011;40:398-406.

10. Taylor W, Gladman D, Helliwell P, Marchesoni A, Mease P, Mielants H, CASPAR Study Group. Classification criteria for psoriatic arthritis: development of new criteria from a large international study. Arthritis Rheum 2006;54:2665-73.

11. Scarpa R, Atteno M, Lubrano E, Provenzano G, D'Angelo S, Spadaro A, et al. The effectiveness and safety of TNF-alpha blockers in the treatment of early psoriatic arthritis: an Italian multicentre longitudinal observational pilot study. Clin Rheumatol 2011;30:1063-7.

12. Gladman DD, Bombardier C, Thorne C, Haraoui B, Khraishi M, Rahman P, et al. Effectiveness and safety of etanercept in patients with psoriatic arthritis in a Canadian clinical practice setting: the REPArE trial. J Rheumatol 2011;38:1355-62.

13. Fransen J, Antoni C, Mease PJ, Uter W, Kavanaugh A, Kalden JR, et al. Performance of response criteria for assessing peripheral arthritis in patients with psoriatic arthritis: analysis of data from randomised controlled trials of two tumour necrosis factor inhibitors. Ann Rheum Dis 2006;65:1373-8.

14. Iannone F, Lopriore S, Bucci R, Scioscia C, Anelli MG, Notarnicola A, et al. Two-year survival rates of anti-TNF- $\alpha$ therapy in psoriatic arthritis (PsA) patients with either polyarticular or oligoarticular PsA. Scand J Rheumatol 2015;44:192-9.

15. Fagerli KM, Lie E, van der Heijde D, Heiberg MS, Kalstad S, Rødevand E, et al. Switching between TNF inhibitors in psoriatic arthritis: data from the NOR-DMARD study. Ann Rheum Dis 2013;72:1840-4.

16. Saad AA, Ashcroft DM, Watson KD, Symmons DP, Noyce PR, Hyrich KL, BSRBR. Efficacy and safety of anti-TNF therapies in psoriatic arthritis: an observational study from the British Society for Rheumatology Biologics Register. Rheumatology 2010; 49:697-705.

17. Fagerli KM, Lie E, van der Heijde D, Heiberg MS, Lexberg AS, $\mathrm{R} \emptyset$ devand $\mathrm{E}$, et al. The role of methotrexate co-medication in TNF-inhibitor treatment in patients with psoriatic arthritis: results from 440 patients included in the NOR-DMARD study. Ann Rheum Dis 2014;73:132-7.

18. Soubrier AS, Bele-Philippe P, Cortet B, Ramdane-Sebbane N, Bacle-Boutry MA, Lemeunier L, et al. Treatment response, drug survival and safety of anti-tumour necrosis factor $\alpha$ therapy in 193 patients with psoriatic arthritis: a twelve-year "real life" experience. Joint Bone Spine 2015;82:31-7. 